\title{
INFORMATIZAÇÃO E REESTRUTURAÇÃO DA HEMEROTECA DA BIBLIOTECA PÚBLICA MUNICIPAL DE LONDRINA
}

\section{COMPUTERIZATION AND RESTRUCTURING OF THE LONDRINA MUNICIPAL PUBLIC LIBRARY HEMEROTECA}

\author{
Zoraide Aparecida Gasparinia \\ Marcos Antonio de Moraes ${ }^{b}$ \\ Leda Maria de Araújoc
}

\begin{abstract}
RESUMO
Objetivo: a pesquisa tem por finalidade registrar o papel e a importância da hemeroteca, espaço de memória, preservação e acesso aos registros do conhecimento, com objetivo de compreender e reconstituir a maneira pela qual 0 espaço informacional se configurou no passado e a grande relevância dos acervos impressos para a mediação, disseminação e compartilhamento da informação histórica. Metodologia: pesquisa exploratória de natureza qualitativa. Resultados: apresentara a importância da reestruturação e informatização da hemeroteca, uma vez que gerou rapidez na busca e recuperação da informação. Conclusão: a reestruturação da hemeroteca foi de suma importância, na reorganização do espaço físico e sequência sistemática dos assuntos dos materiais que constitui-se num acervo documental rico de informações históricas reunidas ao longo destes mais de 40 anos.
\end{abstract}

Descritores: Biblioteca Pública. Hemeroteca. Desenvolvimento de coleções.

\section{INTRODUÇÃO}

A palavra hemeroteca designa uma coleção de recortes de jornais e revistas classificados e indexados, tendo por objetivo auxiliar a leitura e pesquisa da comunidade em geral. Uma hemeroteca não é medida pela

\footnotetext{
a Mestranda em Ciência da Informação pela Universidade Estadual de Londrina (UEL). E-mail: gasparini7@gmail.com

b Doutor em Ciência da Informação pela Universidade Estadual Paulista "Júlio de Mesquita Filho" (UNESP/Marília).E-mail: marcosmoraes@uel.br

c Doutoranda em Ciência da Informação pela Universidade Estadual Paulista "Júlio de Mesquita Filho" (UNESP/Marília). E-mail: le-araujo@hotmail.com
} 
quantidade de recortes, mas sim pela qualidade e relevância das notícias selecionadas, recortadas e da indexação coordenada de cada artigo.

A hemeroteca, setor onde encontra-se coleções de obras periódicas em série da Biblioteca Pública Municipal de Londrina, (BPML) passou por um processo de reestruturação e informatização. Esse processo aconteceu, em decorrência da necessidade percebida de facilitar a busca de informação, notícias, reportagens de cunho histórico e atual aos usuários da Biblioteca Pública Municipal de Londrina.

Desta forma, a pesquisa aborda todo o processo de informatização do modelo conceitual de uma hemeroteca eletrônica, tal como uma coleção de notícias indexadas de diversas áreas do conhecimento, além das etapas percorridas para desenvolvimento e reestruturação desta. Este artigo tem por objetivo descrever os resultados do desenvolvimento de todo o processo de informatização e reestruturação da hemeroteca, sobretudo no que se refere à sua organização conceitual e física, cuja ênfase voltou-se pela escolha de estratégias que visassem aprimorar os processos de busca, recuperação e compartilhamento do acervo da hemeroteca.

A informatização de serviços de informação, tal como uma hemeroteca, propicia maior nível de eficácia e eficiência na busca e recuperação dos artigos, oferecendo um serviço de qualidade à população. Deste modo Optouse pela reestruturação do acervo da hemeroteca por reconhecer sua importância e facilitar o manuseio de um volume significativo de informações.

É importante ressaltar que trabalhar num ambiente com a utilização de tecnologias da informação pode resultar na criação de novos produtos e melhores serviços. Neste sentido, soluções para compartilhamento de informação, armazenamento e disseminação são de grande relevância para subsidiar os trabalhos e a tomada de decisão em ambientes com fluxo de informação (FERNANDES; FERREIRA, [20--]).

A Biblioteca Pública de Londrina é uma instituição social por excelência, que visa a cada dia aperfeiçoar os fluxos informacionais e democratizar 0 acesso à informação, portanto, optou-se pelo uso, na gestão da sua hemeroteca, do Sistema Sophia. A escolha deste software justifica por 
acreditarmos que este gerenciador de informações está bem próximo em atender as demandas da Hemeroteca.

Nesta perspectiva, sendo a Ciência da Informação, um campo interdisciplinar que engloba vários temas relacionados ao nosso objeto de estudo, a "informação", o objetivo principal do serviço de reestruturação e informatização da hemeroteca foi proporcionar uma busca mais precisa das informações, pois, o grande problema era a dificuldade percebida no processo de recuperação da informação desejada pelos usuários, acarretado pelo grande volume da coleção, da falta de critérios atualizados de organização conceitual e física e também pela ausência de um mecanismo de busca ágil, que até então ocorria de forma manual.

\section{DESENVOLVIMENTO DE COLEÇÕES}

Achilles (2014, p. 2) expõe que, "o desenvolvimento de coleções tem sua origem atrelada à necessidade de selecionar materiais para a formação e, consequentemente, para o desenvolvimento de coleções das bibliotecas".

O desenvolvimento de coleções sempre foi ponto crucial para a boa administração de bibliotecas, com o intenso uso das tecnologias nas suas atividades, os processos que envolvem o desenvolvimento de coleções foi afetado, acarretando em sensíveis transformações dos fazeres do bibliotecário em relação à formação dos acervos. Essas mudanças e transformações promoveram, primeiramente, o desenvolvimento do processo de editoração, como veículo inerente à disseminação do conhecimento e propiciou o avanço científico e tecnológico. A multiplicação de publicações ficou mais rápida e facilitou o controle e armazenamento. Tais acontecimentos colaboraram para a limitação, por parte das bibliotecas, em absorver o conhecimento registrado e isso acelerou a busca por instrumentos que pudessem resolver esse problema.

O processo de formação e desenvolvimento de coleções é uma política antiga, desenvolvida para unidades informacionais com objetivo de um crescimento ordenado do acervo, de modo a constituir um equilíbrio para atender ao público real e consequentemente o usuário em potencial. 
Nesse sentido, a missão e os objetivos da instituição que a mantêm orientarão a formação e o desenvolvimento de coleções. De acordo com Weitzel (2012, p.182), "a politica deve descrever a estrutura para a formação das coleções, [...]. Nesse sentido, a missão e os objetivos da biblioteca e da instituição que a mantêm orientam a formação e o desenvolvimento de coleções".

É importante esclarecer que formar e desenvolver coleções vai além de selecionar e adquirir obras. A literatura especializada define desenvolvimento de coleções como um processo cíclico e ininterrupto que contém várias etapas. Dentre elas, estudo da comunidade, ter uma política de seleção, aquisição, desbaste e avaliação (VERGUEIRO, 1989).

Weitzel discorre sobre:

A estrutura para formação de coleções funciona como um esqueleto para abrigar cada parte específica das coleções. Assim, cada item selecionado deve exercer uma função clara no acervo, tal como cada parte do esqueleto: para pesquisa, para 0 estudo, para o trabalho, para o lazer [...], correspondendo ao que foi estabelecido na estrutura (WEITZEL, 2012, p. 182).

Neste sentido, uma das funções da hemeroteca, dentro de uma biblioteca pública, é guardar os registros históricos, preservando a memória da cidade. As hemerotecas são as maiores guardiãs dessa memória. Por ser um acervo composto por recortes de documentos, possibilita o armazenamento somente das informações relevantes para a história local ou regional. Sobre a guarda de documentos históricos Le Goff discorre que:

Desde a Antiguidade, a ciência histórica, reunindo documentos escritos e fazendo deles testemunhos, superou o limite do meio século ou do século abrangido pelos historiadores que dele foram testemunhas oculares e auriculares. Ela ultrapassou também as limitações impostas pela transmissão oral do passado. A constituição de bibliotecas e de arquivos forneceu assim os materiais da história. Foram elaborados métodos de crítica científica, conferindo à história um dos seus aspectos de ciência em sentido técnico (LE GOFF, 1990, p. 471).

Assim, inicialmente o trabalho realizado na Hemeroteca da Biblioteca Pública Municipal de Londrina consistia em analisar, recortar, separar e armazenar diariamente as notícias dos periódicos em pastas temáticas. No momento atual, utilizamos a mesma metodologia de trabalho, no entanto, 
houve reestruturação do espaço, desbaste e descarte de duplicatas. Durante o processo de informatização da hemeroteca, objeto deste artigo, além dos processos anteriormente mencionados, acrescentou-se atividades relacionadas à informatização dos artigos indexados nas pastas, por meio do uso do software Sophia.

Buse (2005), pesquisador da área da Ciência da Informação, em seu estudo identificou que as hemerotecas, de modo geral, mesmo não tendo a mesma estrutura, possuem algumas características em comum. Por exemplo, o tipo do material, coleções e obras seriadas (jornais, revistas e/ou recortes dos mesmos). Sua organização, comumente é feita por título e assunto, bem como seu armazenamento. A principal função de uma hemeroteca destina-se à conservação das informações publicadas periodicamente sobre um determinado assunto, permitindo assim, o resgate e acesso ao produto informacional que foi disponibilizado anos atrás. Além disso, percebe-se que a pesquisa no âmbito da hemeroteca possibilita também o resgate do registro da história, promovendo ao pesquisador relacionar o passado com o presente, buscando as origens dos fatos e a refletir sobre as consequências daquilo que ocorre dia após dia, em uma projeção da história para o futuro.

\section{INFORMATIZAÇÃO DA HEMEROTECA}

O surgimento de novos formatos de materiais requer novos modos de atuar. É preciso catalogar e indexar esse material e disponibilizá-lo aos usuários. Quanto aos periódicos, especificamente, é essencial ofertá-los o mais rápido possível, com o objetivo de atingir os usuários reais e especialmente os potenciais

[...] a pesquisa e recuperação de informação em publicações periódicas assume maior complexidade, se comparada com a pesquisa no universo das monografias. Seja pela extensão assumida por alguns títulos, que chegam a prolongar a sua publicação por mais de um século (OLIVEIRA; MATOS, 2015, p. 187).

Independente do momento de mecanização, industrialização e evolução tecnológica, o elemento que perpassou por todas as fases chama-se informação. A referida constatação abre um cenário de atuação para 
profissionais da informação. Os bibliotecários adaptaram seus serviços e produtos à nova realidade dos seus usuários, no que se refere ao uso das tecnologias. A internet é uma comprovação do uso acentuado das tecnologias no cotidiano das pessoas (SILVA, 2016).

Giordano (2016) em sua tese afirma que o perfil dos usuários de hemerotecas tende a ser diversificado uma vez que os jornais abordam os mais variados assuntos. Assim, coleções armazenadas nesses repositórios são utilizadas para sanar a curiosidade sobre determinado acontecimento ocorrido em uma cidade ou em um país, pode ser uma opção de passatempo ou ainda servir de base para pesquisas sobre assuntos específicos em um determinado período. Porém, mais do que atender à curiosidade de um público que se interessa por temas gerais, pesquisas familiares e assuntos aleatórios presentes nas páginas de jornal e revistas, os registros passíveis de serem recuperados nesses materiais apresentam-se como preciosa fonte de informação no contexto acadêmico. Afinal, a informação jornalística é extraída do cotidiano, sendo um recorte espaço-temporal da realidade, mesmo que uma realidade parcial, figurando muitas vezes como fonte informacional única.

Diante do grande volume de artigos que são recortados e da infinidade de informações geradas, surgiu-se a necessidade de se estudar uma maneira fácil e rápida de disseminação dessas informações. Partindo do princípio que a informatização é necessária e que o trabalho de controle e normalização da linguagem deve ser uniformizado, os funcionários do setor de periódicos encontraram-se diante de um problema. A hemeroteca da BMPL possui diversas pastas, contendo recortes de jornais e revistas de interesse especial para a história e o cotidiano da cidade de Londrina, abrangendo um período que vai de 1980 até os dias atuais. A busca pela informação desejada tinha muita revocação, porém a precisão não estava sendo relevante.

A importância da informatização de uma biblioteca vê-se a dois níveis: os serviços internos: catalogação, gestão de periódicos, aquisições, colaboração entre bibliotecas, entre outros. Também ao nível dos serviços ao público, que estão cada vez mais exigentes nas buscas para suprir suas 
buscas informacionais esses serviços podem ser disponibilizados por meio de catálogo on-line, empréstimo, consulta e acesso à Internet, entre outros.

Para a informatização da hemeroteca da BPML, utilizou-se um sistema de classificação diferenciado para facilitar as pesquisas desse acervo específico. Utiliza-se o sistema alfabético dentro das áreas do conhecimento divididas por assunto e essas áreas se dividem em séries e subséries, tantas quantas forem necessárias. Para os materiais históricos específicos da cidade de Londrina, que foram os primeiros informatizados, utilizamos a sigla $\mathrm{HL}$ (História de Londrina) antes da numeração das pastas.

\section{PROCEDIMENTOS}

Para atingir o objetivo de informatizar e reestruturar o setor de hemeroteca da Biblioteca Pública Municipal de Londrina foram estabelecidas três principais etapas, que quando necessário, se desdobravam em atividades específicas que buscavam atingir o objetivo de cada uma das etapas. A primeira etapa relacionou-se com o estabelecimento de novos modelos de organização física e conceitual do acervo, desdobrando em atividades de classificação e indexação. A segunda etapa consistiu na avaliação e desbaste do acervo da hemeroteca, e por fim, a terceira etapa preconizou a catalogação do acervo no sistema de gerenciamento de bibliotecas Sophia.

No que se refere ao antigo sistema de organização, tendo em vista que a organização desta hemeroteca que possuía uma sistemática de arquivamento com seis acervos no mesmo espaço, sendo eles:

- Acervo Londrina,

- Acervo Londrina História

- Acervo Paraná

- Acervo Paraná história

- Acervo Geral

- Acervo geral retrospectivo

Desse modo, o primeiro procedimento foi selecionar e reestruturar os acervos de forma cronológica. Como existiam dois acervos do mesmo assunto, 
havia assim duplicidade dos materiais. Paralelo a leituras teóricas, iniciou-se os trabalhos unindo os dois acervos que continham a história de Londrina, agrupando-os na mesma pasta temática.

O segundo procedimento foi à seleção e desbaste dos materiais até triplicados nas pastas. Foi um processo exaustivo com o estabelecimento de critérios de seleção. Sendo que a partir daquele momento optamos por estabelecer a inserção de novos recortes referentes ao acervo história de Londrina, sendo assim, apenas ao acervo denominado "Londrina história", visto que, são os com procura relevante. Esta ação gerou complexidade e tempo, posto que o desbaste foi realizando, levando em consideração as novas diretrizes do desenvolvimento de coleções da hemeroteca.

O terceiro procedimento neste processo de reestruturação paralelo ao estabelecimento de normas e seleção, foi à inserção dos artigos (recortes) na base de dados. Os resultados destas ações práticas estão descritas na próxima seção.

\section{RESULTADOS}

Quando iniciamos a pesquisa teórica, assim como as reflexões a respeito da importância da hemeroteca para disseminação, compartilhamento da informação, também como campo de estudo, não mensurávamos a série de problemas que iam ser solucionados no setor da Hemeroteca da BPML com este trabalho.

O mais complexo em nossa hemeroteca, eram os diversos acervos no mesmo espaço. Desta forma, esses acervos foram agrupados dentro da mesma temática, foi um processo exaustivo que demandou um período extenso, pois, além de unir os acervos, esta ação resultou na ampliação otimização do espaço que antes era insuficiente, bem como, na rapidez na busca e recuperação da informação.

Essa nova reestruturação, possibilitou melhoria no atendimento, devido a disponibilização deum terminal de autoatendimento para consulta e recuperação dos artigos. Na sociedade contemporânea a busca pela informação deve se dar de forma ágil, uma vez que as Tecnologias de 
Informação e Comunicação visão sistematizar e facilitar o acesso a qualquer tipo de informação.

Com essas mudanças e transformações do setor, partindo de uma pesquisa teórica e prática, foi possível obter um armazenamento sequencial do acervo que antes não existia, o que dificultava a guarda dos artigos. Além de promover uma busca e recuperação mais eficaz. Para isso foi imprescindível seguir os critérios de seleção adotados.

A respeito do acervo geral e do Brasil foram realizados os mesmos procedimentos de reestruturação e reorganização do setor. No momento atual está sendo realizado o processo agrupamento dos acervos com assuntos do Estado do Paraná. O processo está sendo desenvolvido, seguindo os mesmos critérios adotados para a junção do acervo de Londrina. Assim, o espaço está sendo reorganizado, o material duplicado desbastado e, consequentemente, haverá mais espaço para o crescimento dos dois acervos.

\section{CONSIDERAÇÕES FINAIS}

A hemeroteca da BPML é de suma importância e constitui-se num acervo documental rico de informações históricas reunidas ao longo destes mais de 40 anos. Sendo um acervo necessário para toda e qualquer biblioteca que busca disseminar e compartilhar informação de forma rápida e eficaz. Este trabalho de pesquisa é necessário para toda e qualquer biblioteca que busca disseminar e compartilhar informação de forma rápida e eficaz. Este trabalho de pesquisa e reorganização do setor facilitou a busca e recuperação dos artigos pelos usuários e funcionários. No entanto, ainda é necessário investimentos no setor, como assinaturas de novos títulos de revistas e jornais para ampliação e atualização do acervo.

Quando refletimos a respeito da atualização do acervo, é quase impossível não deparamos com obstáculos. A falta de atualização é uma das principais deficiências das hemerotecas públicas. O processo de aquisição por meio de compras, além de ser burocrático, conta com o descaso governamental, com a falta de políticas públicas locais voltadas para a informação, bibliotecas, livro, leitura e literatura. 
A hemeroteca necessita de materiais atualizados para melhor atender a população e pesquisadores. Para a solução e prevenção de novas "falhas", é urgente e imprescindível as assinaturas de coleções e obras periódicas. Contudo, enquanto essa medida não for atendida, as hemerotecas enfrentarão dificuldades para sua manutenção e para oferecer qualidade em seus serviços. Visto que o objetivo é oferecer o melhor ao público e atender todas as suas necessidades e demandas informacionais. No entanto, para isso é necessário investimento, recursos humanos e financeiros, equipamentos tecnológicos entre outros.

Araújo (2015, p.237), em pesquisa realizada em 2015 a respeito das bibliotecas públicas de Londrina, afirma que as dificuldades são muitas e "[...] precisam ser superadas, problemas desde as instalações físicas, infraestrutura, serviços, a falta de profissionais, de acervo [...]. É necessário estabelecer políticas públicas Municipais em prol das Bibliotecas".

As bibliotecas públicas são ambientes de informação que demandam neste século XXI, de profissionais proativos, com conhecimentos em diversas áreas, que atuem com dinamismo e versatilidade. Que sejam rápidos nas tomadas de decisões e entendimentos sobre as necessidades quanto às atualizações informacionais.

\section{REFERÊNCIAS}

ACHILLES, Daniele. Desenvolvimento de coleções: apontamentos teóricos sobre bibliotecas especializadas. Disponível em:

http://siseb.sp.gov.br/arqs/INT_DESENVOLVIMENTO_DE_COLECOES_Daniel e\%20Achilles\%20Dutra\%20da\%20Rosa.pdf. Acesso em: 30 maio 2019.

ALMEIDA JÚNIOR, Oswaldo Francisco de. Biblioteca Pública: avaliação de serviços. Londrina: Eduel, 2003.

ARAÚJO, Leda Maria. Memória do Sistema Municipal de Bibliotecas

Públicas de Londrina. 2015. 317f. Dissertação (Mestrado em Ciência da Informação) - Universidade Estadual de Londrina, Londrina, 2015.

ARAUJO, Felipe. Hemeroteca. Disponível em: https://www.infoescola.com/curiosidades/hemeroteca/. Acesso em: 15 maio 2019. 
BUSE, Juliana. Hemeroteca sobre saques e invasões do impresso ao digital. 2005. Disponível em:

inttp://sedici.unlp.edu.ar/bitstream/handle/10915/48322/Documento_completo.p df?sequence=1\&isAllowed=y. Acesso em: 25 maio 2019.

DIONNE, Hugues. A pesquisa-ação para o desenvolvimento local. Brasília: Liber livro, 2007.

FERNANDES, Tatiana Brandão; FERREIRA JUNIOR. José Raymundo Costa. Hemeroteca digital: modelo para implementação no centro de biotecnologia da Amazônia. Disponível em:

www.bibliotecadigital. unicamp.br/document/?down=23465. Acesso em: 27 maio 2019.

FONSECA, João José Saraiva da. Metodologia da pesquisa científica. Fortaleza: UEC, 2002.

GIORDANO, Rafaela Boeira. Do jornal à ciência: a hemeroteca digital brasileira como fonte de informação para a pesquisa científica. 2016. $239 \mathrm{f}$. Tese (Doutorado em Ciência da Informação) - Programa de Pós-Graduação em Ciência da Informação, Instituto Brasileiro de Informação em Ciência e Tecnologia, Universidade Federal do Rio de Janeiro, Escola de Comunicação, PPGCI, Rio de Janeiro, 2016.

LE GOFF, Jacques. História e memória. Campinas: UNICAMP, 1990.

Disponível em: https://www.ufrb.edu.br/ppgcom/images/Hist\%C3\%B3ria-eMem\%C3\%B3ria.pdf. Acesso em: 20 dez. 2019.

MILANESI, Luís. Biblioteca. São Paulo: Ateliê Editorial. 2002.

OLIVEIRA, João Carlos Salvador da Silva; MATOS, Álvaro Costa de. Hemeroteca Municipal de Lisboa: património projetado no futuro. Cadernos BAD, Lisboa, 2015, n. 1, jan/jun, p. 177-200. Disponível em: https://bad.pt/publicacoes/index.php/cadernos/article/view/1167/pdf_18. Acesso em: 29 maio 2019.

SANTOS, Antonio Raimundo dos. Metodologia científica: a construção do conhecimento. Rio de Janeiro: DP\&A, 2000.

SILVA, Márcio Bezerra da, RUFINO, Fernanda Maciel. A web 2.0 na informatização de bibliotecas: um estudo de caso. PontodeAcesso, Salvador, v.10, n.2, p.17-38, ago. 2016. Disponível em: www.pontodeacesso.ici.ufb. Acesso em: 29 maio 2019.

TRIPP, David. Pesquisa-ação: uma introdução metodológica. Educação e Pesquisa, São Paulo, v. 31, n. 3, p. 443-466, set./dez. 2005. Disponível em: http://w.scielo.br/pdf/ep/v31n3/a09v31n3. Acesso em: 30 abr. 2019.

VERGUEIRO, W. Desenvolvimento de coleções. São Paulo: Polis, 1989. 
WEITZEL, Simone da Rocha. Desenvolvimento de coleções: origem dos fundamentos contemporâneos. TransInformação, Campinas, v .24 n. 3, p.179190, set./dez. 2012. Disponível em: https://www.scielo.br/scielo.php?pid=S0103-

37862012000300003\&script=sci_arttext\&tlng=pt. Acesso em: 25 maio 2019.

\title{
TITLE: COMPUTERIZATION AND RESTRUCTURING OF THE LONDRINA MUNICIPAL PUBLIC LLIBRARY HEMEROTECA
}

\begin{abstract}
Objective: the research aims to register the role and importance of the hemeroteca, memory space, preservation and access to knowledge records, with the objective of understanding and reconstituting the way in which the information space was configured in the past and the great relevance of printed collections for mediation, dissemination and sharing of historical information. Methodology: exploratory research of a qualitative nature. Results: had presented the importance of restructuring and computerizing the hemeroteca, since it generated speed in the search and retrieval of information. Conclusion: the restructuring of the hemeroteca was of paramount importance, in the reorganization of the physical space and a systematic sequence of material matters that constitutes a rich documentary collection of historical information gathered over these more than 40 years.
\end{abstract}

Descriptors: Public Library. Hemeroteca. Development of collections.

\section{TÍTULO: INFORMATIZACIÓN Y REESTRUCTURACIÓN DE LA HEMEROTECA DE LA BIBLIOTECA PÚBLICA MUNICIPAL DE LONDRINA.}

\begin{abstract}
RESUMEN
Objetivo: la investigación tiene como objetivo registrar el papel e importancia de la hemeroteca, el espacio de la memoria, la preservación y el acceso a los registros de conocimiento, con el objetivo de comprender y reconstituir la forma en que se configuró el espacio de información en el pasado y la gran relevancia de los colecciones para la mediación, difusión e intercambio de información histórica. Metodología: investigación exploratoria de carácter cualitativo. Resultados: había presentado la importancia de reestructurar e informatizar la hemeroteca, ya que generaba rapidez en la búsqueda y recuperación de información. Conclusión: la reestructuración de la hemeroteca fue de suma importancia, en la reorganización del espacio físico y una secuencia sistemática de asuntos materiales que constituye un rico acervo documental de información histórica recopilada durante estos más de 40 años.
\end{abstract}

Descriptores: Biblioteca Pública. Hemeroteca. Desarrollo de colecciones. 
Recebido em: 19.07 .2020

Aceito em: 13.12.2020 